\title{
Infrastructure information management of bridges at local authorities in the UK
}

Ajith Kumar Parlikad MIET, MISEAM

Senior Lecturer in Industrial Systems, Centre for Smart Infrastructure and Construction, Department of Engineering, University of Cambridge,

Cambridge, UK (corresponding author: ajith.parlikad@eng.cam.ac.uk)
Phil Catton

Research Associate, Centre for Smart Infrastructure and Construction,

Department of Engineering, University of Cambridge, Cambridge, UK

Behind the largest infrastructure construction projects currently underway is a system of managing information known as Building Information Modelling (BIM). This represents a collaborative approach to civil engineering and makes use of advances in computer technology to link seamlessly many information repositories together across organisational boundaries. Alongside the developments in BIM, the world of asset management has also seen a major leap forward with the release of ISO 5500x - the family of international standards for asset management. This is now being adopted by many industries - particularly those in the infrastructure sectors - to maximise the value which is returned from their assets. In addition, the Highways Maintenance Efficiency Programme has released a guidance for highway authorities wishing to improve their asset management systems. However, infrastructure managers in local authorities such as county councils are significantly less engaged in both of these developments than their counterparts in strategic infrastructure networks. This paper presents the findings of a study of the 'information system landscape' at local authorities from across England, UK. The study reveals a number of recurring information management challenges that are frequently present. The paper finally provides a number of recommendations with specific reference to information management and encourages councils to consider adopting the standards.

\section{Introduction}

A large amount of research is currently underway to improve the information available to construction companies - developing technologies capable of measuring in new ways, facilitating deployments in places and manners previously impossible. However, in comparison to the design life of the infrastructure being created, construction projects are short lived. Even the most ambitious projects, such as Crossrail in the UK, only take a few years to complete $(\sim 10$ years). whereas the design life is much longer (120 years (Crossrail, 2015)).

As such, there will always be a limit to how useful any information can be to a construction project. However, once the asset is constructed, that same information can be used by different stakeholders throughout its entire life for maintenance or even when it comes to altering or decommissioning the structure. It is easy to underestimate the ongoing cost of operating and maintaining infrastructure assets. Networks such as London Underground are so intertwined with and important to cities, they become almost invisible to the public and are noticed only when they are unavailable through strikes or closure. Construction projects, such as Crossrail or the Thameslink Programme redevelopments, are much more obvious and are frequently in the press - as are their costs. Crossrail, for example, will cost about $£ 15$ billion, between 2009 and 2019 (Crossrail, 2017). Meanwhile, over the same periods, the operation of London Underground will have cost about $£ 20$ billion and that of Network Rail in the region of $£ 100$ billion. Hence, a whole-life perspective needs to be taken for asset information management.

The focus of this paper is on asset information systems of local authority asset owners (LAs), particularly in the context of the management of bridges. While owners of strategic infrastructural assets - such as Network Rail, Highways England or Transport for London - have very mature systems, LAs are not in a position to invest resources in developing their systems to the same level. Yet LAs are still responsible for tens of thousands of assets such as bridges across the country.

To investigate this further, a series of interviews were conducted with LAs from English two-tier ('shire') counties regarding the use of information for the management of bridges. In particular, the purpose of the investigation was to understand the following issues: (a) current practice in bridge information management, (b) the challenges involved in managing information about bridges and (c) awareness of the latest thinking such as Building Information Modelling (BIM) and asset management. This paper presents the results of this review of practice. Based on this, recommendations appropriate for LAs are provided, by drawing on publications from BSI and ISO.

There are three main parts to this paper. Various relevant publications are reviewed in the section 'Background'. The section 'Interviews with LAs' describes the interview process and presents the findings. Based on the challenges recognised in the interviews and potential solutions identified in publications, the section 'Analysis and recommendations to local authorities' concisely suggests recommended actions for LAs.

\section{Background}

Over recent years, many high-profile documents have been published on asset management information systems. Here, an overview of the relevant concepts is provided and the reader is 
given an appreciation of what guidance exists, why it was written and where it may be found. This section will focus on the concept of BIM and its supporting PAS 1192 standards and the asset management standards PAS 55:2008 and ISO 55000:2014.

\section{$\mathrm{BIM}$}

BIM is sometimes unfairly thought of as the logical extension of three-dimensional (3D) computer-aided design (CAD) models. But it is significantly more involved than a simple $3 \mathrm{D}$ representation of a structure is. Fundamentally, BIM aims to transform the civil engineering industry at large, by streamlining the collaborative information storing/sharing processes of building and operating civil assets. A BIM model will consist of many layers of information, allowing different views of a structure to be created for different purposes. It will include not only dimensional information, but also details of materials, relationships between components (e.g. for clash detection prior to installation), suppliers, asset management information and many more aspects (Holness, 2006). There is the scope to include almost any information that may be required through any part of the life cycle of an asset (Eastman et al., 2011).

BIM models can also contain the additional dimension of 'time' (known as 'four-dimensional BIM'). This dimension allows the model to be used as an aid for construction processes and sequencing - for example, identifying the order in which components need to be assembled (Hamledari et al., 2017). This facilitates the use of techniques more commonly associated with manufacturing industries, such as 'just-in-time'. Cost data are included as the fifth dimension ('five-dimensional BIM'), helping with cost estimations and spend projections ( $\mathrm{Lu}$ et al., 2016). More recently, sixth and seventh dimensions have been proposed, but accepted definitions of what these actually mean have not yet stabilised (O’Keeffe, 2013).

The benefits of BIM for the design and construction phases of infrastructure assets are well documented (Barlish and Sullivan, 2012; Bryde et al., 2013). The use phase of structures, particularly those for transport infrastructure, is, however, significantly longer than their construction phase and indeed often more costly. As such, using BIM presents those responsible for the use phase (such as asset managers) with a useful opportunity (Pärn et al., 2017).

An organisation's information systems can be measured against fairly standardised definitions of 'BIM maturity levels' (NBS, 2017). Level 0 is described as simple CAD drawings, consisting of just lines and arcs. Level 1 systems include two-dimensional or 3D models (as distinct from drawings, i.e. parameterised, relational documents rather than static fixed drawings). Level 2 requires a much more comprehensive system than merely a loose collection of files and documents; BIM level 2 needs a managed structure, adhering to standardised processes. Crucially, at this level various different models should be somehow integrated, either by being explicitly combined into one, large, federated model or by being seamlessly linked using intermediate systems ('middleware'). BIM level 3 builds on the mindset which will have developed by reaching BIM level 2, but is yet more pervasive and systems are fully integrated. It requires fully standardised systems, using Industry Foundation Classes (buildingSmart, 2017) and the International Framework for Dictionaries (IFD) (ISO, 2007) to allow information to be stored and shared seamlessly between systems, organisations, projects and even countries. Crucially, however, BIM level 3 also facilitates using the information held in the model for the ongoing asset and facility management of the structure. Progressively more effort and investment is required to move up each maturity level, as the aspects covered become increasingly complex, involved and all-encompassing.

Recognising a tendency for the UK to 'not get full value from public sector construction', in 2011 the Cabinet Office laid out the Government Construction Strategy (Cabinet Office, 2011: p. 3). Among its recommendations was that '[g]overnment will require fully collaborative 3D BIM (with all project and asset information, documentation and data being electronic) as a minimum by 2016' (Cabinet Office, 2011: p. 14). This started the BIM ball rolling in earnest in the UK, mandating the entire supply chain to adopt 3D BIM.

\section{PAS 1192 suite of standards}

PAS 1192-2:2013 (BSI, 2013) describes the minimum requirements for BIM level 2, and therefore compliance with the Government Construction Strategy mandate. PAS 1192-2:2013 is mainly aimed at construction projects, rather than existing assets, and so there is an emphasis on 'Project Information Models'. It recommends the development of 'Employer Information Requirements', which is a 'pre-tender document setting out the information to be delivered, and the standards and processes to be adopted by the supplier as part of the project delivery process' (BSI, 2013: p. 4).

Focussing more on the ongoing management and operation of an asset, PAS 1192-3:2014 (BSI, 2014a) introduces and describes the concept of an 'Asset Information Model' (AIM). The AIM is defined in the PAS as 'data and information that relates to assets to a level required to support an organisation's asset management system' (BSI, 2014a: p. 3). One of the fundamental messages that comes from this PAS is that every organisation needs to specify 'Asset Information Requirements' (AIR) for their assets, and these must developed for the purposes of satisfying the 'Organisational Information Requirements' (OIR). The OIR outlines the requirements for information to meet the needs of the asset management system in addition to other organisational functions. The AIR will specify the data and information that needs to be captured and fed into the AIM. Clearly, a clearly aligned wholelife asset information strategy is essential to achieve these objectives.

PAS 1192-3:2014 also recommends that organisations develop a common data environment (CDE), which is a 'single source of information for any given project or asset, used to collect, manage, and disseminate all relevant approved files, documents and data for 
multi-disciplinary teams in a managed process' (BSI, 2014a: p. 4). Note that the CDE does not mean that all information needs to be kept in a single database - data can be distributed, but without duplication and clearly established linkages.

PAS 1192-4:2014 (BSI, 2014b) describes a standardised approach to store and transfer asset information. It mandates that Construction Operations Building Information Exchange (Cobie) be used to this end, but sets out a specific methodology for its use, including how information should be specified and requested. The Cobie framework is a formal schema for asset information (Yalcinkaya and Singh, 2015). In its most 'raw' form, it is a very large spreadsheet, allowing all information regarding an asset to be recorded in a structured, repeatable way. It should eliminate many data quality issues by forcing entries to use a common language for example, the same valve component may be described either as a 'one-way valve' or as a 'non-return valve'. This kind of ambiguity is unacceptable for BIM level 2, where there should be 'a single version of the truth' at all times, for all things. As such, in order to meet the UK government's BIM level 2 mandate, Cobie must be used. The BIM Task Group has a large library of templates and other guidance for using Cobie (BIM Task Group, 2017).

Finally, PAS 1192-5:2015 (BSI, 2015) addresses issues of security and specifies the processes that will assist organisations in identifying and implementing appropriate and proportionate measures to reduce the risk of loss or disclosure of information. The key trend in the development of standards is that they have continued to increase in scope and aim to cover the whole life cycle of assets.

\section{ISO 55000:2014: asset management system}

Based on PAS 55:2008 (BSI, 2008), the international standard ISO 55000:2014 - published in 2014 - further develops the definition of good practice in asset management. It is not a specification of an asset management system; rather, it defines requirements for such a system and provides guidance as to how it may be implemented.

As with PAS 55:2008, 'whole-life value' is at the centre of the concepts set out in ISO 55000:2014 (ISO, 2014), but has been generalised to apply to any asset type rather than just physical assets. Both PAS 55:2008 and ISO 55000:2014 include not only strategies for improving the management of assets, but also strategies for improving the process of asset management itself.

\section{Highway Infrastructure Asset Management Guidance Document}

Post-dating PAS 55:2008, much of the relevant concepts and themes are collated in this guidance document and targeted towards local highway authorities. Written by Atkins on behalf of the Highways Maintenance Efficiency Programme (HMEP), the document (UK Road Liaison Group, 2013) introduces asset management as a discipline which should be pursued by local authorities.

PAS 55:2008 and ISO 55000:2014 describe what asset management is and the benefits and general requirements. The HMEP document describes how UK highway authorities can actually achieve those ideals. This document is further discussed in the section 'Adoption of asset management best practice'.

\section{Interviews with LAs}

Approach

While no two local authorities are identical, their asset stocks are similar across the country. As such, local authority asset managers were selected as the topic of interest for this particular piece of work, with a specific emphasis on bridges. In order to investigate the widest asset stock most efficiently, English two-tier county councils (sometimes referred to as the 'shire counties') were identified as target interview candidates, as shaded in Figure 1.

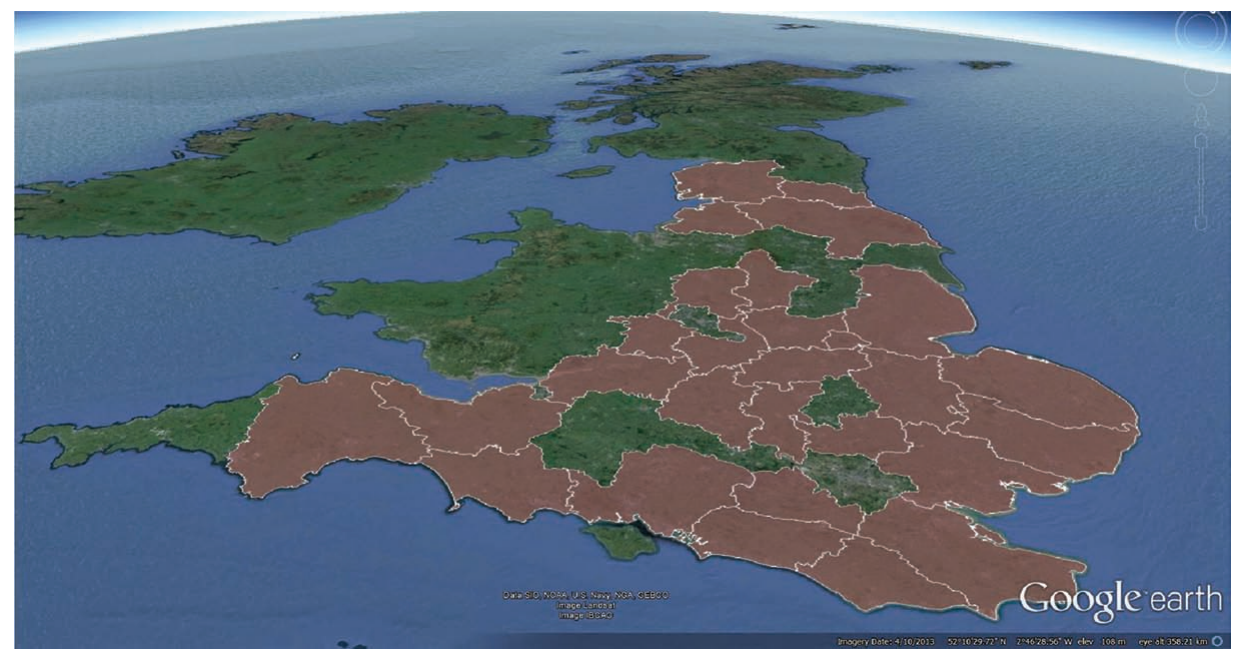

Figure 1. Diagram of english two-tier county councils identified as interview targets (courtesy of Google Earth) 
Twenty-one out of 27 two-tier county councils were interviewed as part of this study. These collectively represent $41 \%$ of the land area of England and nearly $70 \%$ of the population. Eighty-two per cent of these target asset owners were interviewed, such that owners of more than 50000 bridges and several hundreds of kilometres of retaining walls have fed into this study.

Interviews were conducted with a range of engineering staff at the county councils, often with several separate discussions to ensure that a representative output could be reached. Each interview followed the same structure, with a mix of quantitative and qualitative questions. There were also more open-ended discussions, aimed at impartially teasing out challenges without risking 'leading' questions.

There were broadly four topics covered in the interviews.

- Context: Details about the asset stock for which the LA is responsible and their yearly budget. (quantitative answers)

- Information system 'landscape': What asset information is held and in what format and on what systems? (qualitative answers)

- Information challenges: Considering both information systems and the information itself, what causes the biggest

'headaches'? (qualitative answers from open-ended questioning)

- Awareness: Awareness and uptake of BIM and asset management standards. (quantitative and qualitative answers)

\section{Findings: context}

As can be seen in Figure 2, there is a wide variation in the size of asset stocks across the country. As England has a diverse geographical landscape, this is not surprising. Even when accounting for the land areas of counties (Figure 3, left) and their populations (Figure 3, right), different LAs will manage disproportionately different asset stock sizes. Interesting to observe in Figure 3 are counties such as North Yorkshire, which is sparsely populated but has a large number of bridges, which places greater financial burden on the LA. On the other hand, small counties such as Worcestershire have a disproportionately large number of bridges, which makes maintenance planning complicated.

Budgets are generally dictated to the asset managers, as is the distribution of revenue (i.e. operations and maintenance) and capital expenditure. Revenue budgets are often insufficient, so the asset managers rationalise the use of the capital budget as 'capital maintenance'. The summary of statistics in Table 1 shows the number of bridges (minimum/maximum refers to the number of bridges in the LA that has the smallest/largest number of bridges) and amount of revenue budget available to bridge managers highlighting the minimum (i.e. the LA which has the least amount), the maximum (the LA with the most amount of money) and the average and standard deviation across all the LAs. The table clearly highlights the financial constraints within which bridge asset managers operate.

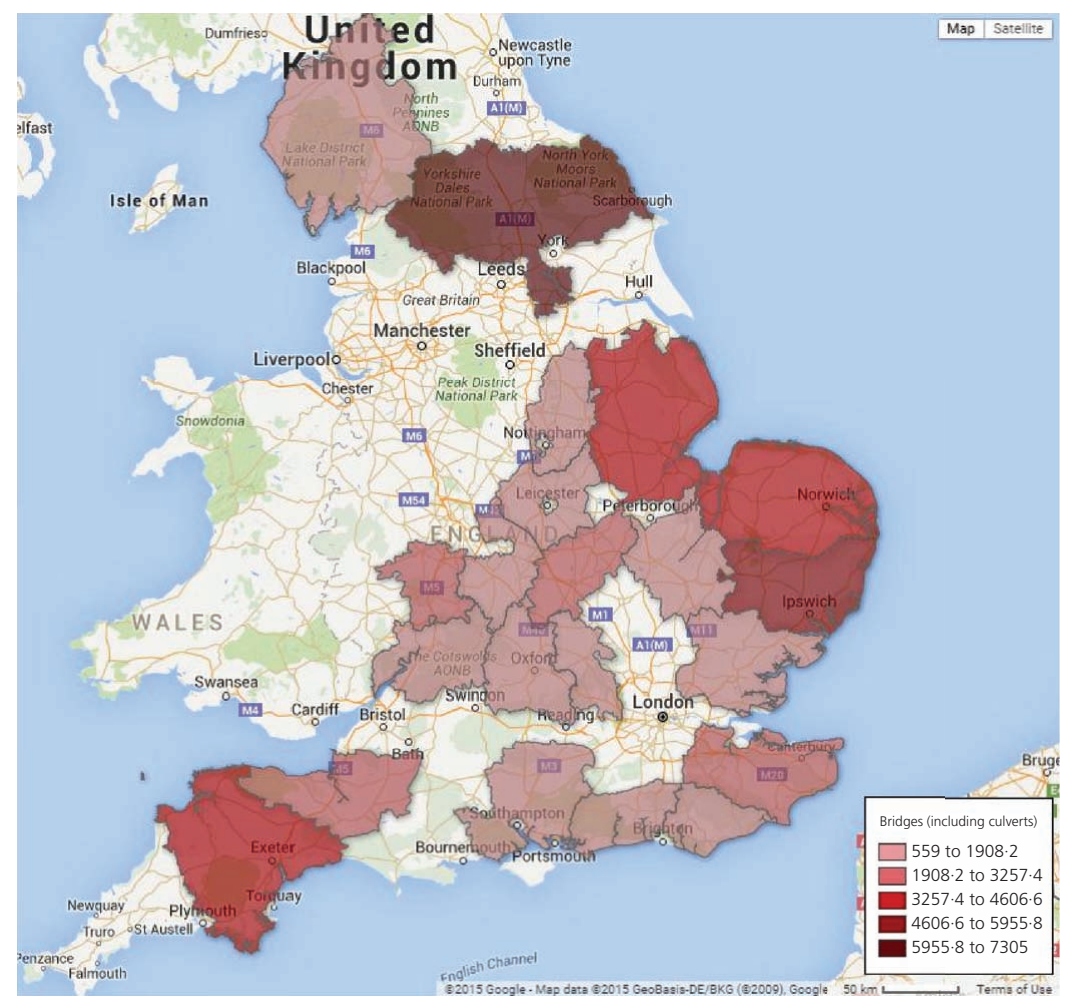

Figure 2. Diagram of absolute number of bridges in interviewed LAs. C2015 Google - Map data. @2015 GeoBasis-DE/BKG (C2009), Google 


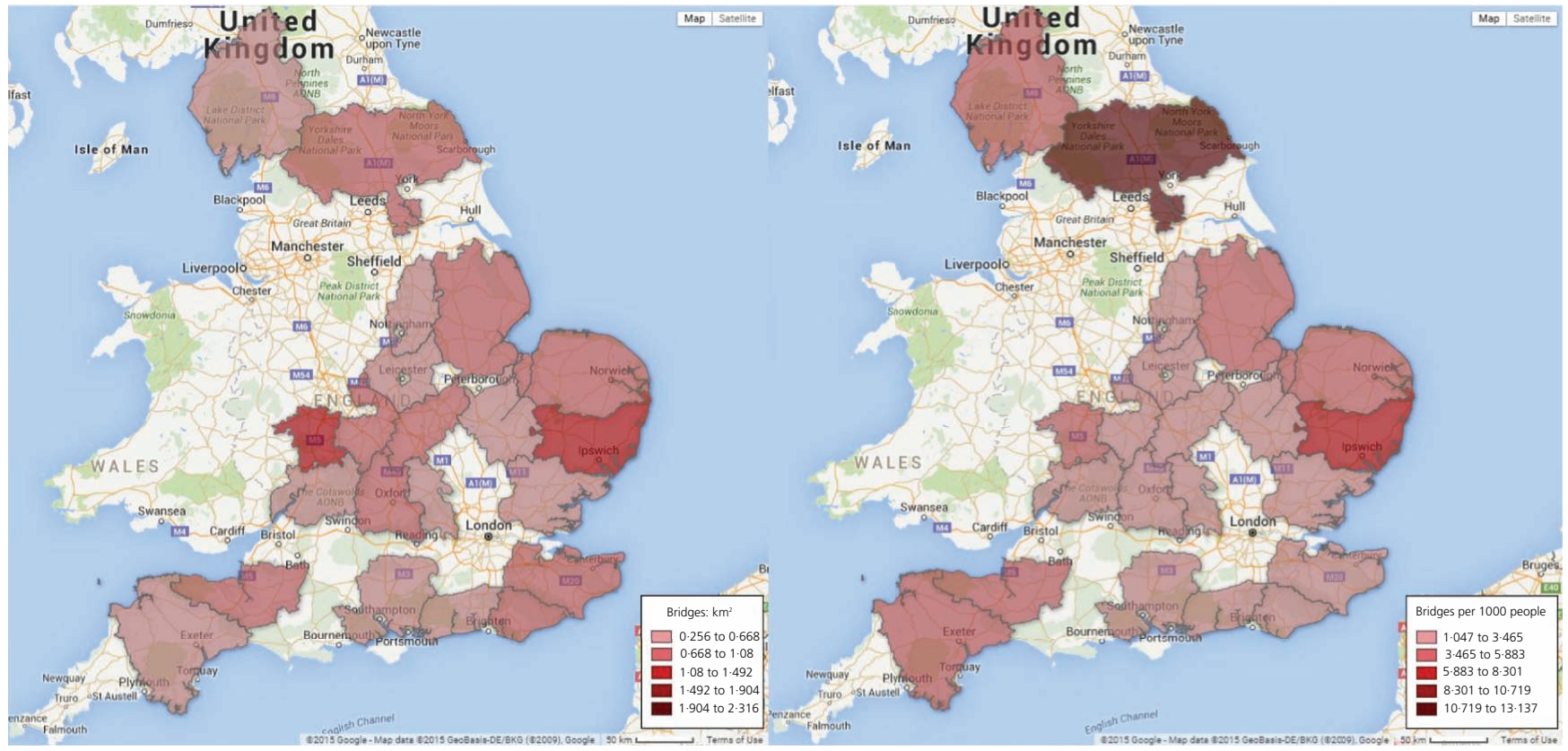

Figure 3. Diagram of number of bridges (left) per square kilometre and (right) per 1000 people living in interviewed LAs. @2015 Google Map data. @2015 GeoBasis-DE/BKG (@2009), Google

Table 1. Summary of LA asset statistics

\begin{tabular}{|lllll|}
\hline $\begin{array}{l}\text { Measure } \\
\text { (per LA) }\end{array}$ & Minimum & Maximum & Average & $\begin{array}{l}\text { Standard } \\
\text { deviation }\end{array}$ \\
\hline $\begin{array}{c}\text { Number of bridges } \\
\text { Number of bridges }\end{array}$ & 0.26 & 7300 & 2420 & 1746 \\
$\begin{array}{c}\text { per square } \\
\text { kilometre }\end{array}$ & 1.32 & 0.65 & 0.27 \\
$\begin{array}{c}\text { Bridges per } \\
\begin{array}{l}1000 \text { people } \\
\text { Total budget for }\end{array}\end{array}$ & 1.05 & 12.14 & 3.41 & 2.72 \\
$\begin{array}{c}\text { bridges: } \mathrm{f} 1000 \\
\text { Budget per bridge: } \\
\text { f1000 }\end{array}$ & 0.100 & 4675 & 2297 & 1117 \\
\hline
\end{tabular}

\section{Findings: information system landscape}

As the UK has a fairly old transport network, with arguably one of the oldest networks in the world, many of these assets are very old, including 'heritage' assets in some cases dating back many hundreds of years. Clearly, with every passing year, the likelihood of asset owners possessing good-quality information decreases, particularly before such a time when the information is digitised.

The source of information about bridges is predominantly based on regular inspections. Bridges are subject to a regime of general inspections and principal inspections every 2 and 6 years, respectively (Atkins, 2005; TSO, 2017). However, LAs are allowed to increase or decrease the inspection intervals based on a robust and fully documented risk assessment. The guidance provides a standard methodology for assessment of bridges during these inspections. However, in practice, the quality of assessment is variable and subjective and relies on the experience of personnel carrying out the inspection.

Six different software systems are used for asset information management, as shown in Figure 4. The typical information held

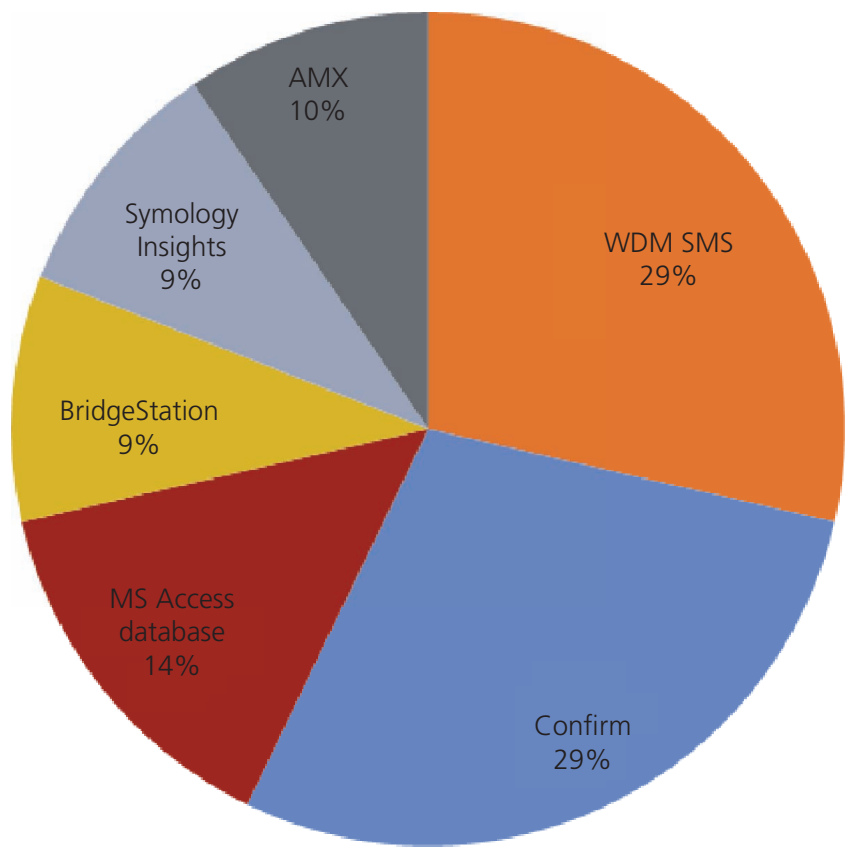

Figure 4. Distribution of software systems used by LAs asset managers interviewed. AMX, Asset Management eXpert; WDM SMS, WDM Structures Management System; MS, Microsoft 
by the LAs regarding the bridges can be found in a publication by the County Surveyors Society (2002).

The capability of the software systems used range from a simple database such as MS Access to asset registries such as WDM SMS and life cycle planning/analysis tools such as AMX and BridgeStation (2017). Other tools such as Symology Insights and Confirm offer generic asset management solutions and are not specifically designed for bridges. A frequent complaint among asset managers was that the software they use is only a 'bolt-on' to some other asset information management system - for example, an additional 'module' for a highway management system. As can be seen in Figure 4, only 19\% of the LAs use tools that are specifically designed for bridges and structures. Even among these, the use of the advanced analytics capabilities of the solutions was not common - they were mostly used for keeping bridge inspection data.

The maturity of solutions varies significantly. Some LAs have fully integrated cloud/smartphone-based systems with everything stored online - inspectors can enter data from the field, which are automatically pushed to a centralised database. Meanwhile, other LAs have almost exclusively paper based systems.

An effect of this is that the specific information which is held and how/where/for how long also varies from one LA to the next. However, most LAs had the recent inspection reports readily available - any information generated in the last decade or so is typically of reasonable quality. However, older records were not reported to be readily available, and if they are, the quality was found to be questionable. This means that although the current condition of their bridge stock was understood, the lack of good historic data prevents LAs from being able to develop consistent deterioration models to inform maintenance and investment planning and to assess the risk from their bridge portfolio.

\section{Findings: information challenges}

LAs were asked to describe explicitly their biggest informationrelated challenges. The most frequently recurring themes specified are listed in Figure 5. Cited in about a third of all interviews were concerns with information being generally absent - that is, gaps in the information repository, where one would expect the information to exist.

Information relating to the ownership of assets was cited by nearly a quarter of LAs. Many authorities accepted that simply knowing what assets for which they are responsible is difficult and not always a 'given'. This may be from where assets have been adopted without records being comprehensively updated or where records of several geographically nearby assets (yet still distinctly separate entities) have become inadvertently merged into one single record.

Nearly one in four LAs is currently struggling with their responsibilities for central government accounting. The Chartered Institute of Public Finance and Accountancy (CIPFA) requests all LAs to provide them with both gross replacement costs and depreciated replacement costs (CIPFA, 2017). The requisite information must obviously be available before it can be entered into a costing tool. While only one in five LAs explicitly described 'cleaning up' the poor data quality in their systems, more than $80 \%$ mentioned 'missing information' as a challenge during the open-ended discussions and many more of the topics arising relate to poor data quality. In order to fulfil the CIPFA requirements correctly, the input data quality needs to be remedied before the spreadsheet can be complete - which again is a significant undertaking when asset stocks are so large.

Before the current generation of asset information management software systems, many LAs used their own MS Access database to store their information. Because these were generally 'home grown' and developed completely in-house, there were almost as many

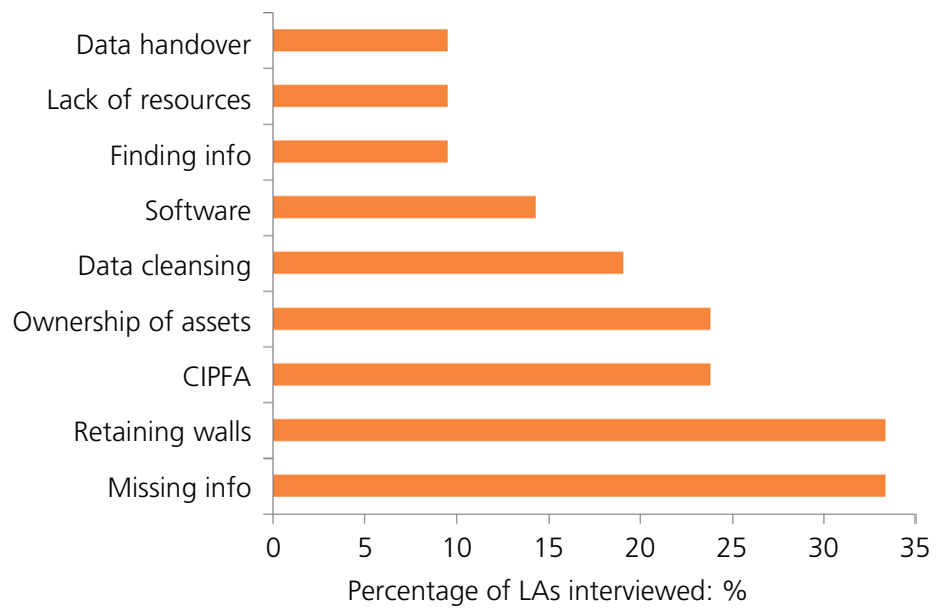

Figure 5. LAs citing top challenges as a percentage of all LAs asked 
systems as there were LAs, although occasionally geographically nearby LAs shared databases. As such, their quality and utility varied - some were fantastic and the asset managers lament their passing, while others are relatively happy with the new 'off-the-shelf' software packages. Other data quality issues relate to ambiguity in records (such as 'unknown material' and 'material unknown'), units of measurement (either numbers being provided without units, leading to metres being confused with millimetres, or using metric calculations with imperial measurements), illegibility (e.g. from poorquality scans) or out-of-date records. Several LAs struggle with organising the sheer quantity of information that they hold. As office and storage space has been squeezed over the years, paper has suddenly had to be eliminated. This has led to masses of scanned documents which are poorly indexed and therefore very difficult to search. For example, all documents for a given bridge - drawings, calculations, correspondence and photographs - may have been scanned and stored with unhelpful non-descript filenames.

Some LAs suggested that a root cause of many data quality issues was the timing of the handover of information to them. Counties have been combined, split up and recombined in different permutations many times, and so merging systems is likely to create problems. Similarly, when new assets are constructed (either individual assets or collections, such as a new housing estate), comprehensive information may not be handed over to the LA and possibly not in the most useful format.

Many of these challenges would be technically easy to solve - at worst, surveying each bridge to populate databases, but there are simply not the resources available. The LAs generally know what problems they have and how they could be solved, but are too busy maintaining their asset stock to invest time in improving their information systems.

\section{Findings: awareness of relevant developments BIM}

Most LAs interviewed are aware of BIM, with about a quarter either currently implementing systems or have an intention to do so in the near future. Among those who know about BIM, views are polarised. While some are really bought into the concept, the majority remain to be convinced of the benefits that BIM can offer to bridge owners and managers.

There are strong views in both directions, with some particularly scathing comments about the inappropriateness of BIM for asset information management at the local level. Recurring comments were that BIM would not provide any additional utility over existing systems and that a system developed specifically for the purposes of bridges would be more useful. Generally, those not intending to implement BIM felt they simply do not have the resources to spare. Several suggested that a 'corporate' push would be required before they would start the process.

As can be seen in Figure 6, about $15 \%$ or those interviewed believed they knew what BIM was - but it quickly transpired that

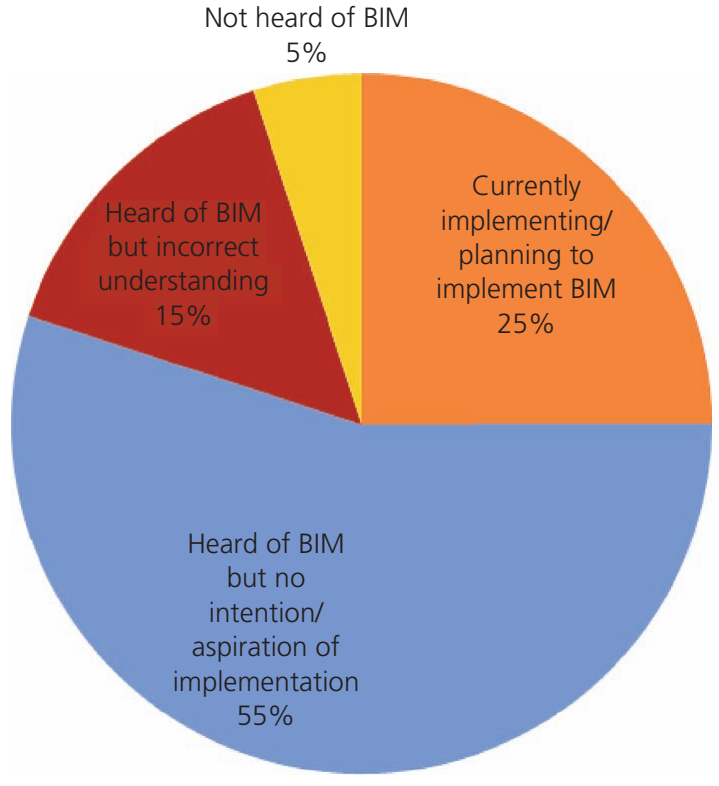

Figure 6. Distribution of the awareness and interest of BIM among LAs interviewed

their conceptions were incorrect. Perhaps because of language used in early documents regarding BIM, it appears that many believe it is nothing more than a 3D CAD model of an asset. Among the $55 \%$ of the LAs that were aware of BIM, a common perception was that BIM is not only inappropriate for their needs, but not realistically achievable without considerable investment. With limited expertise, budget and resources, getting on the BIM journey for these LAs were low in priority.

The 2011 Government Construction Strategy report used the clause ' $[\mathrm{g}]$ overnment will require fully collaborative $3 \mathrm{D}$ BIM (with all project and asset information, documentation and data being electronic) as a minimum by 2016' (Cabinet Office, 2011: p. 14). Perhaps because the 3D nature was inadvertently emphasised and the broader concept of BIM was insufficiently explained at this point, an incomplete view was presented. It is perhaps this misconception that hides the wider benefits of BIM, and even those who do understand the concept are prejudiced against it and fail to realise its implications.

\section{Asset management standards}

Local authorities typically work according to the HMEP guidance document (UK Road Liaison Group, 2013), as this describes the minimum practices that must be undertaken. It also advocates, to some extent, whole-life thinking. Thanks to the HMEP guidance, LAs are taking a long-term view when possible - for example, investing in waterproofing bridges to reduce future maintenance costs.

But awareness of PAS 55:2008 and ISO 55000:2014 is very low, as the bridge asset managers have simple not had need to come 
Infrastructure Asset Management

Volume 5 Issue 4
Infrastructure information management of bridges at local authorities in the UK Parlikad and Catton
Which asset management standards are you aware of?

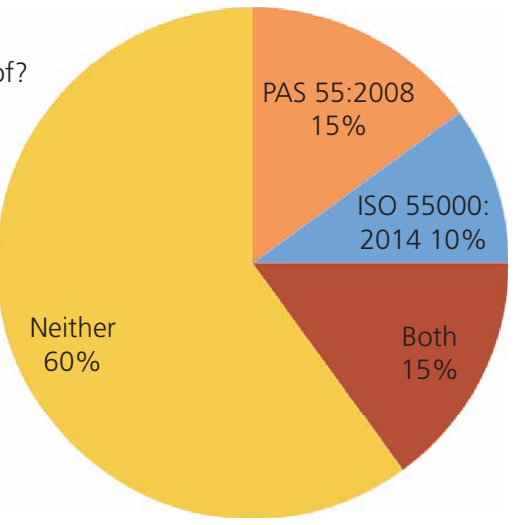

Figure 7. Awareness of PAS 55:2008 and ISO 55000:2014 among LAs interviewed

Are you currently implementing or planning to implement PAS 55:2008 or ISO 55000:2014?

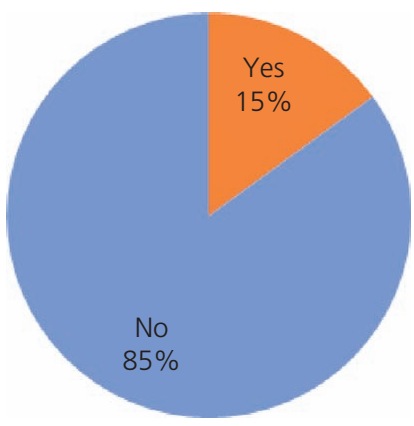

Figure 8. Uptake of asset management standards among LAs interviewed

across them. Indeed, nearly two thirds had not heard of either standard, as shown in Figure 7.

Despite the lack of penetration of these standards in the sector, $15 \%$ of interviewed LAs are either currently implementing PAS 55:2008 or ISO 55000:2014 or are intending to do so soon (Figure 8). This proportion is approximately representative of the split of opinions on 'asset management' as a concept.

Even though a key function of those interviewed is, literally, 'the management of assets', many felt that asset management does not describe their role, taking the view that it is more of a bureaucratic matter of accountancy. This represents a clear barrier to the uptake of ISO 55000:2014 and any future standards regarding asset management.

\section{Analysis and recommendations to local authorities}

Many of the observed challenges currently appear to be matched by opportunities presented by recent developments in technology and practice. This section will discuss approaches which have potential to improve the underlying issues behind some of the most endemic challenges.

\section{Move towards BIM level 2}

Existing information systems at LAs are frequently a collection of disparate systems, using a variety of media. This is periodically exacerbated by large collections of new information being either inherited (e.g. when LAs have merged systems) or handed over (e.g. when assets on a new development are adopted). As described in the section headed 'Building Information Modelling', BIM level 2 mandates not only that data should be held in a structured, digital format, but also a common schema in which that data should be stored. This means information may be easily exchanged between information holders.

Some LAs suggested the trustworthiness of their information was questionable, with either conflicting or outdated content. Challenges arising from this, and indeed to locating information within the system, would also be improved by a BIM level 2 system. A key concept is for the information system to hold a single version of the truth, such that it is impossible to use incorrect data for any decisions - and yet an auditable trail of information leading up to 'the truth' will still be available.

Many LAs interviewed were very averse to implementing BIM systems. To some extent, this is understandable, as the concept appears to have been mis-sold to the sector. More still suggested that they will not approach BIM until their hands are forced. There is also the feeling that BIM is not only inappropriate for their needs, but also not realistically achievable. This is unfortunate, as there appears to be many relevant advantages that could be realised through the use of BIM. It appears, however, that since the 2011 Government Construction Strategy mandate of BIM level 2, a critical mass of industry interest has been reached. There has been an enormous investment in developing enabling technologies and approaches, and it now seems unlikely that BIM will not be adopted more widely for private projects. It is reasonable to predict that BIM will therefore become the actual information management approach for civil engineering generally. At such time, LAs are unlikely to be able to avoid its use, and so adopting BIM for their own systems as much as possible before then would be advisable. Existing supply chains will eventually be forced to adopt BIM as it becomes more pervasive, which will add yet more impetus for adoption within LAs.

Of course, there are hundreds of LAs across the country and thousands of counterparts in other countries, facing similar information-related challenges. Perhaps a pragmatic way forward for such asset owners to adopt BIM gradually is to petition suppliers of their existing asset information management systems to bring their software in line with the tenets of PAS 1192. This would be challenging individually, but collectively, user groups will have a stronger voice. One LA interviewed, for example, struggled to get improvements made to the software and so formed a national users' group. This allowed common issues 
(both challenges and suggestions) to be agreed on by a large sample of the company's customer base, in turn leading to greater influence and escalation of ideas.

\section{Risk-based approach to improving data quality}

Poor-quality information was frequently mentioned as a barrier to calculating the replacement costs in accordance with CIPFA standards and in general for asset management.

Information quality (or data quality) can been defined simply as the 'fitness for use' of information (or data). Many studies have shown that poor information quality can have a significant impact on decision-making. Poor information quality can manifest in different dimensions - for example, accuracy, completeness, timeliness, understandability and relevance. One specific - yet illustrative - example of data quality issues were entries such as material unknown against unknown material. Of course, it is not ideal that it is unclear as to what material an element is constructed from, but at least it is a 'known unknown', and when looking at individual occurrences of these two descriptions, it is clear what they mean. But when it comes to comparing thousands of instances of elements against one another, this inconsistency in recording can become problematic.

Similarly, when some measurements are given in metres, some in millimetres and others in imperial units, the mass application of calculations across many hundreds of entries in a database becomes very difficult and unreliable. Worse still is that it may not be obvious that a calculation has used spurious inputs, and so the incorrect result may become the basis for decisions. Recording of dates (which can be written in many formats, such as 'dd-mmyy', 'mm, dd, yy' and 'yyyy-dd of mmm') is another classical example.

It is essential that asset managers take action to improve the quality of data they hold. Once that is achieved, steps must be taken to ensure that the quality of data remains good thereafter (this often requires the development of an information management strategy and an information governance process). Nevertheless, as many asset managers agree, this is not trivial - in terms of both time and cost. The authors recommend that a riskbased approach be taken to tackle data quality problems. Understanding and quantifying the risks posed by poor-quality data is essential in identifying the priority areas to focus on, prioritising data quality improvement projects (e.g. BIM adoption) and developing a business case for such projects (Borek et al., 2014a). Tools and methodologies such as the one presented by Borek et al. (2014b) can help in supporting risk-based information quality management.

\section{Adoption of asset management best practice}

While many LAs remained to be convinced of asset management as a discipline, its underlying goal is to maximise the value which can be obtained from assets. This means not merely 'reducing costs', but also 'increasing benefits'. Getting more output for less input seems counter intuitive, but by taking a structured and, most importantly, long-term view of assets encourages investments to be made that may not 'normally' be justified.

It may take several years before returns can be seen on these investments, which in the context of an environment susceptible to electoral cycles and other political pressures may seem a long time. However, in the context of an infrastructural engineering asset such as a bridge, it quickly becomes apparent that taking a long life cycle view is the only rational approach.

The concept of whole-life value is central to asset management processes proposed by PAS 55:2008, and ISO 55000:2014. Although huge savings may not be immediately realised, over a few years, LAs will start to reap the benefits. A systematic approach to understanding how an asset affects value for different stakeholders over its life and how value can be used to make asset management decisions is necessary (Srinivasan and Parlikad, 2016, 2017).

The HMEP guidance document offers practical steps which can be taken by LAs and other highway authorities. These are summarised in Table 2 alongside suggestions as to their implications on asset information management.

This report's recommendation to adopt asset management best practices specifically concerns the desire to improve an LA's asset information. As such, the table also describes how each of HMEP's recommendations may impact on improving information quality.

\section{Conclusions}

The interviews in this study have identified a number of common challenges with asset information systems and the information held within them, which appear to be widely faced by local authority asset managers. Of course, every LA is different, with different existing systems in place. Different regional geographies dictate the asset stocks, but the organisational history is equally important when it comes to the information on those assets.

The challenges identified can be broadly categorised into three groups according to their apparent underlying causes: (a) shortfalls of the asset information systems, (b) shortfalls of the asset information itself and (c) lack of resources to solve the problems. The key takeaways from this research are as follows.

BIM should be seen as not only more than a 3D model, but as a philosophy and a systematic approach to the management of asset information. Integration of BIM with the asset information systems is essential if the councils and other asset owners are to obtain value from BIM. Failure to understand what data should be linked with the BIM models is one of the primary causes of disillusionment on the part of asset owners. It is critical to follow the recommendations of PAS 1192-3:2014 when creating the BIM models - beginning with the OIR and deriving the AIM from it. 
Table 2. The 14 recommendations from HMEP guidance document with implications for asset information management

Recommendation Implications for asset information management

1 Develop an asset management framework

2 Actively pursue two-way communication of relevant information to relevant stakeholders

3 Develop and publish an asset management policy and strategy

4 Develop a performance management framework

5 Maintain an asset register and regularly review the quality, currency, appropriateness and completeness of all asset management data

6 Adopt life cycle planning

7 Develop and regularly update a programme of prioritised works for a rolling 3- to 5-year period

8 Senior decision makers should commit to the implementation of asset management

9 Make the case for asset management by clearly explaining the wider benefits at stake

10 Provide appropriate training to ensure competency in asset management

11 Embed assets' risk management with the strategy, identifying strategic, tactical and operational risks and mitigation measures

12 Asset management systems should be appropriate and accessible

13 Regularly review and improve the asset management framework's performance

14 The asset management framework should be benchmarked against that of other authorities
An asset management framework should be created specifically for the needs of the organisation, but this must explicitly include considerations of the requirements for data gathering, storage, reporting and management. Data must be treated as an asset.

Communication of information is not just the dissemination of plans, but should be a 'twoway street', where information can be shared in both directions. Note that relevant information may be held by other asset owners (such as Network Rail or Highways England). A reciprocal arrangement of information sharing could be reached.

Development - and publication - of an asset information management policy and strategy should go hand in hand with the asset management counterparts. The information management policy and strategy should be aligned to - and satisfy the needs of - the asset management policy and strategy. This is essential for defining the AIM in accordance with PAS 1192-3:2014

Developing performance indicators to measure the data quality of the asset information management system may help target efforts towards its improvement. For example, if an inspection report for a random bridge is audited, what percentage of critical information is missing/out of date/untrustworthy? Measuring the quality of data in terms of the risks posed by poor-quality data to decision-making provides a good approach to performance measurement of data management systems. This will also help address a critical question: how good is 'good enough' in terms of data quality.

The inclusion of this recommendation indicates the importance that HMEP places on the availability and quality of asset information. Just as components have a life expectancy, so do data. Inspection reports are an obvious example, as these are required at set intervals, but other types of information may change over time, such as ownership and usage this should be considered in the overall framework. Systematic update of asset data is critical to ensure the usability of the data and hence its value.

Although the sentiment for recommendation 6 in the guidance relates to decision-making and maintenance strategies, these must be based on good-quality information, which is therefore a prerequisite part of the overall strategy.

Again, 'works' in this context refer to physical improvements to assets - but investments in the information system must also be factored in. This is particularly critical in a world where innovations in data management and analytics is happening at an accelerated pace.

The overall strategy should be considered as one entity, not as a collection of disparate approaches. As such, it is essential that the information management aspects are appropriately included. Then, once a commitment to the plan as a whole is made, commitment to information-related articles is implicit.

The requirement of calculating replacement costs for CIPFA each year provides a clear argument for why a good-quality and complete set of information is necessary - but there are many other examples to include as necessary.

Poor-quality data often result from human errors and/or incompetence. Effective training and motivation of employees is essential to ensure the quality of data.

Poor-quality information not only represents operational and tactical risks in terms of inefficiencies, but may also be considered a strategic risk if public safety is put at risk, or other significant liabilities could arise. This emphasises the need to understand and quantify the risks posed due to poor information quality.

Identifying appropriate and practical levels of data quality is essential.

Regularly review information systems, and ensure that the data and information held in them are trustworthy.

The interviews in the present study have shown that, even in the relatively limited set of LAs included, there are fairly similar systems and challenges across the country. There is already a good network in place, so there are good opportunities for peer to peer learning.
However, if the information captured within the BIM model is of poor quality, it fails in its objective. Data need to be improved before these can be incorporated into the model. There are many automated methods to redress this. Perhaps a good value option could be to not only clean up the data, but also investigate what other lessons may be learned by a thorough - yet automated analysis of the asset information systems.
A structured approach for asset management is as recommended by the HMEP guidance, and seeing information as an asset is critical for success. BIM should not be seen as an end in itself, but as a means to achieving improved value from the assets.

Fortunately, there is a national drive to address the challenges identified in the paper, as local authorities do not face them alone. 
The construction industry at large has now been mandates with implementing BIM level 2 for all public projects. Reaching this standard of collaborative information management will be of huge benefit to the first of those underlying challenges. Eventually, skills, technology and experience will filter through to local authorities - but the sooner they are actively embraced, the sooner and more comprehensively those benefits will be seen.

Public spending has decreased over the last few decades, and this is not set to change. Local authorities have therefore adapted to doing 'the same, with less'. However, the latest guidance for achieving best practice in managing assets identifies principles for achieving 'more, with less'. The UK is a thought leader in asset management processes, with British standard PAS 55:2008 becoming the basis for the international asset management standard ISO 55000:2014. There is currently a lot of excitement in the field, and this contagious energy has spread to the UK Roads Liaison Group, leading to the HMEP issuing guidance for highway authorities to pursue these standards. In following that guidance, despite less resources than may be desirable, asset managers will return significant extra value for their asset stocks and the information systems supporting them.

Further, the government is now looking beyond BIM level 2 with the Digital Built Britain vision initially set out in its level 3 strategic plan (HM Government, 2015) and more recently in its Industrial Strategy report (HM Government, 2017). This vision seeks to "digitise the entire life-cycle of our built assets finding innovative ways of delivering more capacity out of our existing social and economic infrastructure, dramatically improving the way these assets deliver social services to deliver improved capacity and better public services' (University of Cambridge, 2017). This initiative is further supported by the National Infrastructure Commission (2017), which encourages further research and innovation to ensure that data generated about infrastructure assets is managed and exploited in a way that delivers improved outcomes for citizens and productivity for the nation.

\section{REFERENCES}

Atkins (2005) Management of Highway Structures - a Code of Practice.

The Stationery Office, London, UK

Barlish K and Sullivan K (2012) How to measure the benefits of BIM - a case study approach. Automation in Construction 24: 149-159, https:// doi.org/10.1016/j.autcon.2012.02.008.

BIM Task Group (2017) CoBie 2012 UK. BIM Task Group, London, UK See http://www.bimtaskgroup.org/cobie/ (accessed 30/05/2017).

Borek A, Parlikad A, Woodall P and Tomasella M (2014a) A risk-based model for quantifying the impact of information quality. Computers in Industry 65(2): 354-366, https://doi.org/10.1016/j.compind.2013.12. 004

Borek A, Webb J, Woodall P and Parlikad A (2014b) Total Information Risk Management: Maximising the Value of Data and Information Assets. Morgan Kauffman, Burlington, MA, USA.

BridgeStation (2017) BridgeStation. See https://www.bridgestation.co.uk (accessed 01/06/2017)

Bryde D, Broquetas M and Volm JM (2013) The project benefits of Building Information Modelling (BIM). International Journal of
Project Management 31(7): 971-980, https://doi.org/10.1016/j. ijproman.2012.12.001.

BSI (2008) BSI PAS 55:2008: Asset management. BSI, London, UK.

BSI (2013) PAS 1192-2:2013: Specification for information management for the capital/delivery phase of construction projects using building information modelling. BSI, London, UK.

BSI (2014a) PAS 1192-3:2014: Specification for information management for the operational phase of assets using building information modelling. BSI, London, UK.

BSI (2014b) BS 1192-4:2014: Collaborative production of information. Fulfilling employer's information exchange requirements using COBie. Code of practice. BSI, London, UK.

BSI (2015) PAS 1192-5:2015: Specification for security-minded building information modelling, digital built environments and smart asset management. BSI, London, UK.

buildingSmart (2017) IFC Overview Summary. buildingSmart, Surrey, UK. See http://www.buildingsmart-tech.org/specifications/ifc-overview (accessed 01/06/2017)

Cabinet Office (2011) Government Construction Strategy. Cabinet Office, London, UK.

CIPFA (Chartered Institute of Public Finance and Accountancy) (2017) Code of Practice on Local Authority Transport Infrastructure Assets Supporting Documents. CIPFA, London, UK. See http://www.cipfa. org/policy-and-guidance/local-authority-transport-infrastructure-assets (accessed 01/06/2017).

County Surveyors Society (2002) Bridge Condition Indicators. CSS Bridges Working Group, Trowbridge, UK.

Crossrail (2015) Crossrail Sustainability Report 2015. Crossrail, London, UK.

Crossrail (2017) Crossrail - Funding. Crossrail, London, UK. See http:// www.crossrail.co.uk/about-us/funding (accessed 30/05/2017).

Eastman C, Teicholz P, Sacks R and Liston K (2011) BIM Handbook: $a$ Guide to Building Information Modeling for Owners, Managers, Designers, Engineers and Contractors. Wiley, Hoboken, NJ, USA.

Hamledari H, McCabe B, Davari S and Shahi A (2017) Automated schedule and progress updating of IFC-based 4D BIMs. Journal of Computing in Civil Engineering 31(4), https://doi.org/10.1061/(ASCE) CP.1943-5487.0000660.

HM Government (2015) Digital Built Britain: Level 3 Building Information Modelling - Strategic Plan. s.1.: HM Government, London, UK.

HM Government (2017) Industrial Strategy: Building a Britain Fit for the Future. HM Government, London, UK.

Holness GVR (2006) Building Information Modeling. ASHRAE Journal 48(8): 38-46.

ISO (International Organization for Standardization) (2007) ISO 120063:2007: Building construction - organization of information about construction works - part 3: framework for object-oriented information. ISO, Geneva, Switzerland.

ISO (2014) ISO 55000:2014: Asset management - overview, principles and terminology. ISO, Geneva, Switzerland.

Lu Q, Won J and Cheng J (2016) A financial decision making framework for construction projects based on 5D Building Information Modeling (BIM). International Journal of Project Management 34(1): 3-21, https://doi.org/10.1016/j.ijproman.2015.09.004.

National Infrastructure Commission (2017) Data for the Public GoodNIC Report. National Infrastructure Commission, London, UK.

NBS (2017) BIM Levels Explained. NBS, Newcastle upon Tyne, UK. See https://www.thenbs.com/knowledge/bim-levels-explained (accessed 30/ $05 / 2017)$.

O'Keeffe S (2013) Synergy of the Developed 6D BIM Framework and Conception of the nD BIM Framework and nD BIM Process Ontology. $\mathrm{PhD}$ thesis, University of Southern Mississippi, Hattiesburg, MS, USA.

Pärn E, Edwards D and Sing M (2017) The building information modelling trajectory in facilities management: a review. Automation 
in Construction 75: 45-55, https://doi.org/10.1016/j.autcon.2016.12. 003 .

Srinivasan R and Parlikad A (2016) Whole-life Value-based Decision Making in Asset Management. Thomas Telford, London, UK.

Srinivasan R and Parlikad A (2017) An approach for value-based infrastructure asset management. Infrastructure Asset Management 4(3): 87-95, https://doi.org/10.1680/jinam.17.00003.

TSO (The Stationery Office) (2017) Inspection of Highway Structures. TSO, London, UK, BD63/17.
UK Road Liaison Group (2013) Highway Infrastructure Asset Management Guidance Document. Department for Transport, UK University of Cambridge (2017) Centre for Digital Built Britain: BIM Level 3. See https://www.cdbb.cam.ac.uk/BIMLevels/BIM3 (accessed 12/2017).

Yalcinkaya M and Singh V (2015) Examining the evolution of COBie standards in Building Information Modelling for facilities management. Proceedings of the 32nd CIB W78 Conference 2015, 27-29 October, Eindhoven, the Netherlands.

\section{How can you contribute?}

To discuss this paper, please submit up to 500 words to the editor at journals@ice.org.uk. Your contribution will be forwarded to the author(s) for a reply and, if considered appropriate by the editorial board, it will be published as a discussion in a future issue of the journal. 